\title{
Hybrid vigor
}

\section{To the editor:}

I appreciate the passion of your June editorial "Hybrid rigor mortis" (Nat. Biotechnol. 21, $585,2003)$, but it seems to me you have missed a significant reason why setting up a hybrid company in an emerging biotech space makes sense.

I agree that fashions wash over the industry and currently hybrids are in vogue. While your criticisms sometimes apply, in some cases, there are good reasons to be a hybrid. The reason that we have set up a hybrid business is that we find the tools side of the business is intricately enmeshed with our discovery business. When we set up Proteome Systems (Sydney, Australia), proteomics was (and still is) in an embryonic state. We had always planned and still do plan to take a significant position in the discovery/therapy area but on reviewing discovery/therapy companies, we found that they invariably did not invest sufficiently in innovation; instead, they ended up relying on existing technology. Having long experience in the protein area, we understood that the existing tools in proteomics were inadequate, so we set up a business that involved innovating the tools area and partnering with major corporations with big distribution networks to get the products to market. Using this structure there is a demand-pull to get products properly finished and into the market place. These not only generate cash but also provide robust technologies for our discovery programs.

Four years on, we find that discovery and technology are intimately tied up, each crossfertilizing the other. In the longer term, it may make sense to separate the businesses, but for the foreseeable future, having them together is very powerful. Of course, that presupposes that we are competitive in both the spaces we operate. To enter a space in an uncompetitive way is fraught with dangers. However, the challenges faced by some of our competitors indicate the dangers of being too narrowly focused in an emerging area.

It's not surprising to us that drug developers are interested in accessing new technologies. When we partner on a discovery program, our technology edge is seen as a real bonus. Clearly, fee-for-service contract research and innovation may get tangled up, and this is the reason we separated the contract research aspect of our business into a separate joint venture with Charles River Laboratories (Wilmington, DE, USA).

I thus take issue with your broad generalization that hybrid companies obfuscate and conceal. Surely, these attributes relate to the nature of personalities, rather than the structure of the business. Our view of investors is that they want to see evidence of a business plan that can survive in the short term and deliver a strong upside in the long term. We think our hybrid model is providing that.
Your comment about the $\mathrm{CFO}$ of a business being either strong on accounting practice/credit control pricing, versus capital raising has some sense, but I don't believe any emerging biotech business can afford to have only one of these two skill sets. Sure, it may be that the CFO is stronger in one of the two, but elsewhere in the business you need to balance these skills.

In summary a hybrid model works for us (and our investors).

\section{Keith Williams}

Proteome Systems, 35 Waterloo Road, North Ryde, Sydney, NSW 2113, Australia.

e-mail:keith.williams@proteomesystems.com

\section{Rediscovering plant-based drugs}

\section{To the editor:}

Lutz Müller-Kuhrt's commentary 'Putting nature back into drug discovery' in the June issue (Nat. Biotechnol. 21, 602, 2003) makes some very compelling arguments about the desirability of natural products research in the

pharmaceutical industry. It echoes a previous commentary published in Nature Biotechnology ${ }^{1}$, 'Prescription for an ailing pharmaceutical industry,' which promotes 'alternative' approaches, such as the application of screening technology to newly available natural product libraries. However, despite such timely critiques, there is as yet little sign that the pharmaceutical industry is rediscovering the potential of plants.

This seeming reluctance might be understandable if the only way to 'revisit' plants was the traditional one of screening plant phenotypes, and if the only reason to do so was disappointment experienced with other drug discovery technologies.
However, there is a new and much more compelling reason to reexamine the medicinal potential of the plant kingdom, namely the emergence of plant genomics.

We surmise that the implications of the genomics revolution for natural products research have yet to be fully appreciated by the pharmaceutical industry. Thus, although Müller-Kuhrt begins with the statement "the human genome has provided...innumerable starting points for new drug discovery," he makes no mention of the extraordinary diversity of compounds that might be available if the genomes of complex plants could be exploited for drug discovery. The challenge of realizing this goal was posed to the biotechnology community several years $\mathrm{ago}^{2}$. The subsequent emergence of a range of genomic and proteomic tools, many applicable to plants and not requiring complete genome sequencing, suggests that we may soon begin to achieve this goal, effectively launching a new era in 